\title{
Non-caseating submental tuberculous lymphadenopathy: A case report
}

\author{
M. E. Asuquo ${ }^{1 *}$, V. I. Nwagbara ${ }^{1}$, S. Akpan ${ }^{1}$, G. Ebughe $^{2}$, T. Ugbem ${ }^{2}$, I. M. Asuquo ${ }^{3}$ \\ ${ }^{1}$ Department of Surgery, University of Calabar/University of Calabar Teaching Hospital, Calabar, Nigeria; \\ *Corresponding Author: mauefas@yahoo.com, mauefas54@gmail.com \\ ${ }^{2}$ Department of Pathology, University of Calabar/University of Calabar Teaching Hospital, Calabar, Nigeria \\ ${ }^{3}$ Department of Curriculum and Teaching, Faculty of Education, University of Calabar, Calabar, Nigeria
}

Received 10 May 2013; revised 20 June 2013; accepted 10 July 2013

Copyright (c) 2013 M. E. Asuquo et al. This is an open access article distributed under the Creative Commons Attribution License, which permits unrestricted use, distribution, and reproduction in any medium, provided the original work is properly cited.

\begin{abstract}
Chronic peripheral lymphadenopathy in adults is an indication of pathology of which tuberculosis is the commonest in the developing countries. Presented is a 36-year-old with a huge chronic Submental lymphadenopathy in a seronegative patient of 7 years duration. Histology revealed non-caseating tuberculosis. Tuberculosis should be considered in Submental lymphadenopathy. Despite the long duration, the absence of cold abscess, and or sinus formation may be an indication of the non-caseating tuberculous lymphadenopathy.
\end{abstract}

Keywords: Tuberculosis; Submental Lymph Node; Non-Caseating Granuloma

\section{INTRODUCTION}

Chronic peripheral lymph node enlargement in adults is an indication of an underlying disease that may pose a diagnostic dilemma to physicians [1]. The commonest lymph node group affected is reported to be the cervical, the clinical manifestation varies with the challenges of diagnosis not unusual $[2,3]$. Tuberculosis (TB) has been reported as a common cause of chronic lymphadenopathy in the developing countries and one of the most common of all extra pulmonary (TB) [4,5]. However, in the developed countries with the rarity of infections, malignnancies are reported as the predominant cause of peripheral lymphadenopathy [1]. In developing countries in Asia and Africa where tuberculous infection is common and other granulomatous infections rare, the presence of granulomatous features on histology are suggestive of TB [3]. We present this case of florid non-caseating Submental tuberculous lymphadenopathy in a human im- munodeficiency virus (HIV) seronegative patient to highlight its unusual presentation; diagnostic challenge due to ulceration from topical herbal medication, florid lesion in an unusual group of lymph node without any identifiable primary lesion.

\section{CASE REPORT}

A 36 years old applicant (engineer) presented to the surgical out patient department (SOPD) as a referral from the general out patient department with a 7-year history of an anterior neck swelling. The swelling began as a nodule, which he felt but was not visible, however increased gradually to the size at presentation. There was no associated fever, cough, and night sweats. There was no history of trauma or dental pain, mass was painless and not associated with pain or difficulty in swallowing. There was no swelling in any other part of the body. He sought treatment in some hospital facilities (private and government) to no avail. Two months prior to presentation, he applied topical herbal preparation that resulted in a wound hence his presentation to the University of Calabar Teaching Hospital (UCTH), Calabar.

Examination revealed a young man in relative good health, afebrile, and not pale. There was a firm, painless, lobulated, ulcerated, and immobile mass in the Submental region of the neck. It measured $8 \mathrm{~cm} \times 6 \mathrm{~cm}$. The edge of the ulcer was slopping with the floor that showed granulation tissue with some spots with sloughs and fixed to the underlying structure, Figures 1(a) and (b). Examination of the oral cavity, ear nose, and throat, chest and abdominal examination were normal. A clinical diagnosis of Submental lymphadenopathy was made.

Full blood count (FBC) showed: haemoglobin 12.9 $\mathrm{g} / \mathrm{dl}$, white blood cell $6.5 \times 19^{9} / \mathrm{l}$ (neutrophils $40 \%$, eosinophils $2 \%$, and lymphocytes $58 \%$ ), human immunodeficiency virus (HIV) serology was negative and urinaly- 


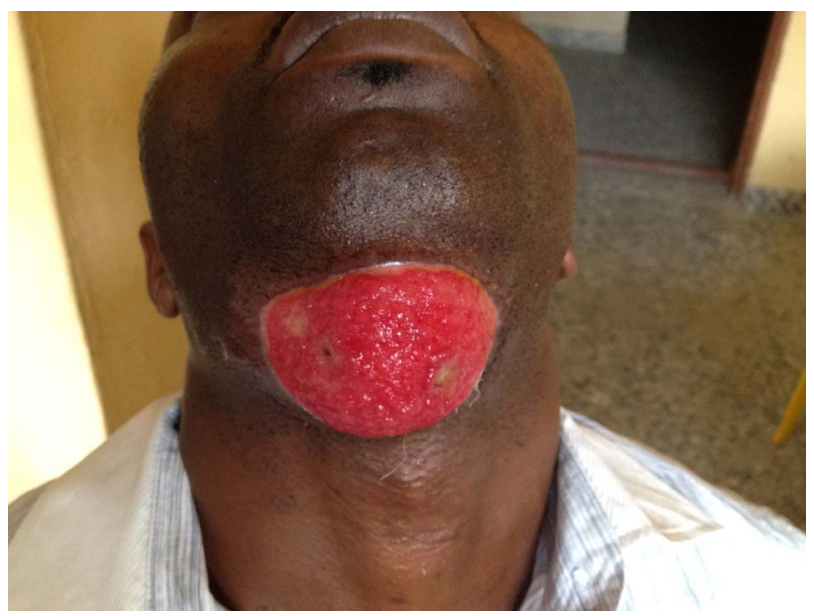

(a)

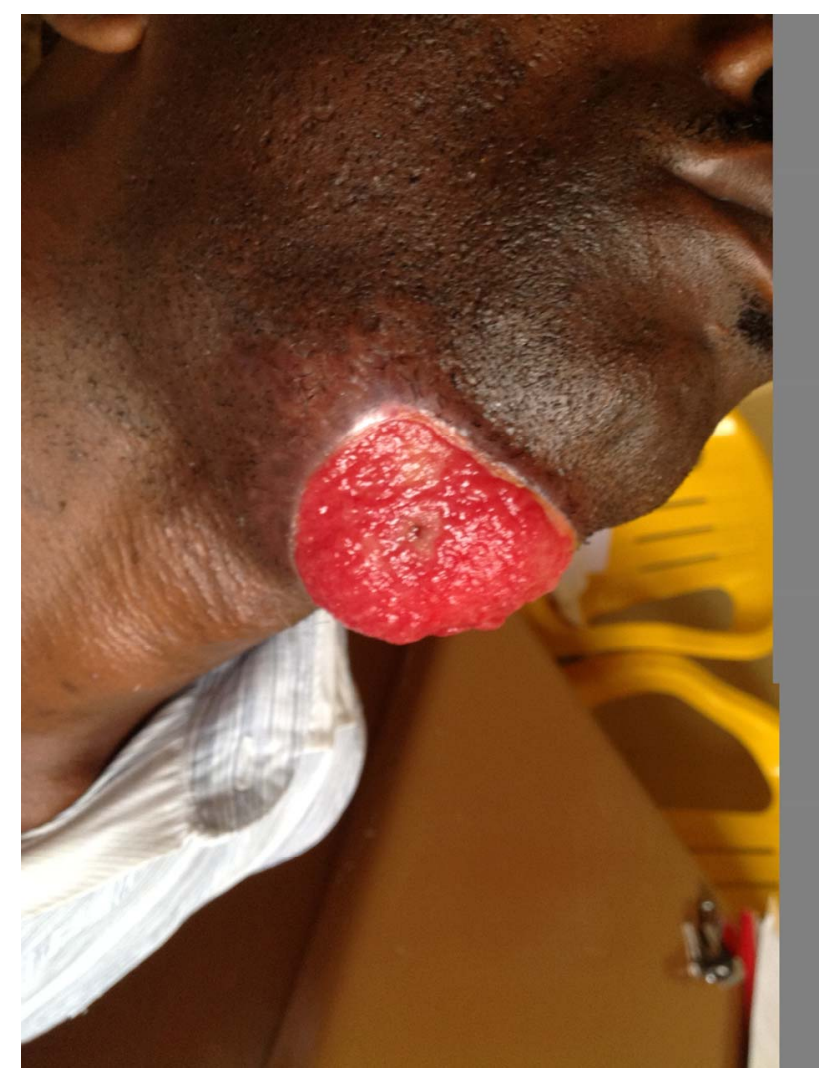

(b)

Figure 1. (a) Clinical photograph of submental lymphadenopathy (Anterior view); (b) Clinical photograph submental lymphadenopathy (Lateral view).

sis was normal. Chest X-ray was normal, ultrasonography reported, predominantly solid heterogeneous mass, lobulated in outline. It appeared to arise from the subcutaneous tissue encroaching on the muscle plane, possibly lymphoproliferative disorder, or fibrolipoma. Fine needle aspiration biopsy (FNAB) reported a haemorrhagic background with mature lymphocytic infiltrate and occasional histiocytes. Histopathology report showed numerous non- caseating granulomas consisting of epitheloid cells, lymphocytes, plasma cells, and fibroblasts, interspersed by occasional multinucleate giant cells. The surrounding stroma was fibrocollagenous-non-caseating granuloma, Figures 2(a) and (b).

Follow up in the SOPD while awaiting result of histology revealed healing of the ulcer with the mass persistent. Following the diagnosis of Submental tuberculous (non-caseating) lymphadenopathy, he was referred to the endemic disease unit for further management.

\section{DISCUSSION}

Tuberculosis ranks second as the leading infectious cause of death in the world after HIV [6]. The emergence of HIV introduced a new component to the epidemiology of TB with extra pulmonary TB including lymphadenopathy TB being more common [7]. Several reports from the tropics describe TB and other infectious aetiology as major causes of lymph node enlargement [8]. The

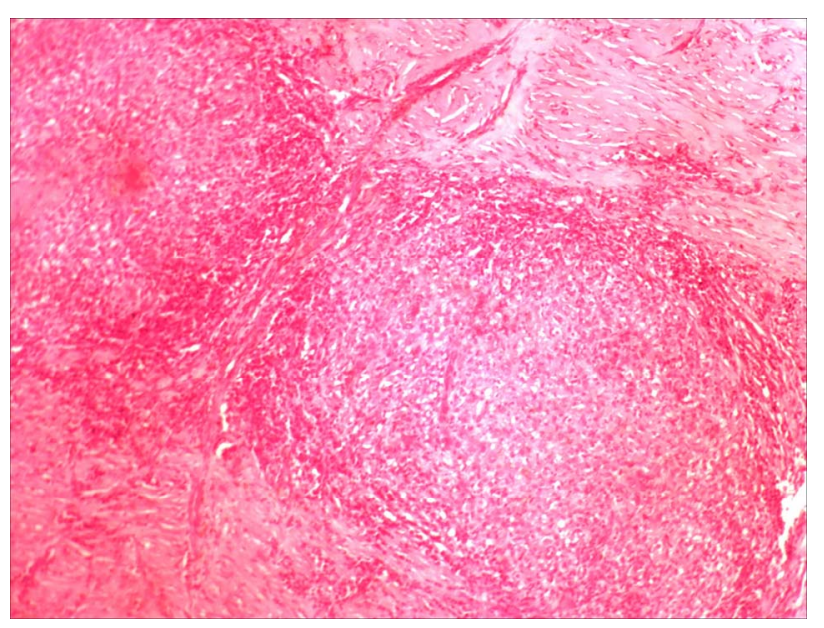

(a)

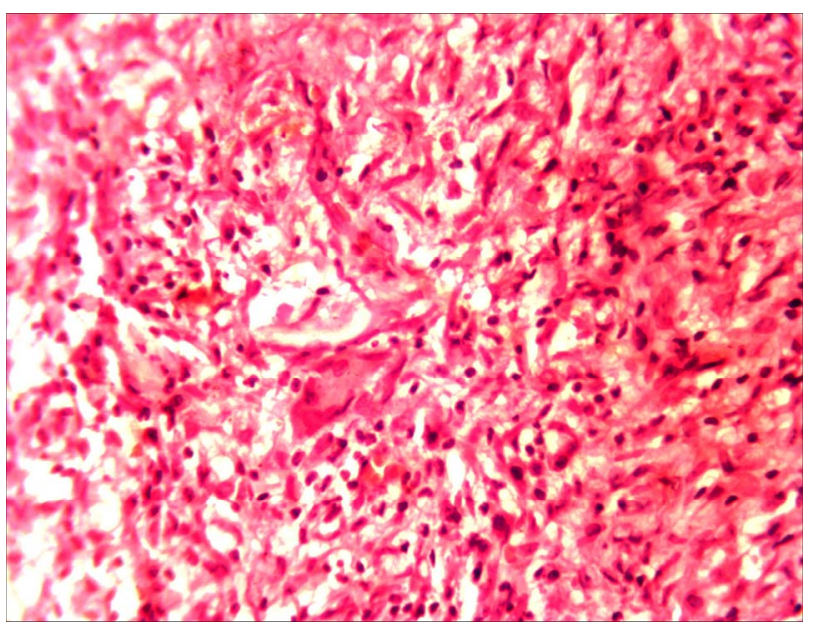

(b)

Figure 2. (a) Non-caseating granuloma H \& E ×40; (b) Noncaseating granuloma $\mathrm{H} \& \mathrm{E} \times 100$. 
commonest site of tuberculous lymphadenopathy reported was cervical. Its involvement of cervical lymph nodes has been known a long time as Scrofula or the Kings Evil [9]. Olu-Eddo and Omoti reported lymphadenopathy as the single commonest cause of cervical lymphadenopathy constituting 35\% of cases [4], and in Saudi Arabia, Al-Sohaibani reported 28\% [10]. This communication describes a huge tuberculous lymphadenopathy in an HIV seronegative patient in an uncommon location for tuberculous cervical lymphadenopathy.

Tuberculous lymphadenopathy is largely confined to the cervical lymph nodes mostly because tonsils and adenoids provide an easy portal of entry for inhaled mycobacteria [5]. It may also result from lymphatic or haematogenous dissemination from an original focus in the lungs [5], our patient had no identifiable dental or oral lesion. However, some lesions may be healed without being detected and may be the case in our patient whose evaluation revealed no primary focus despite the huge Submental lymphadenopathy.

Majority of TB is diagnosed on clinical grounds with or without histological appearance of the biopsy [5]. Active lesions are seen as characteristic granulomatous inflammatory reaction that forms caseating and non-caseating tubercles [6]. Our patient's histologic features were consistent with non-caseating TB, Figure 2. It is less common (20\%) and described as hypertrophic. The firm consistency was in keeping with the clinical evaluation despite the long duration of the lesion; this variety was unlikely to form cold abscess and eventually a sinus seen in the caseating form. The non-caseating TB is seen in patients with good immunity [11], consistent with our patient.

In the authors' setting traditional healers, enjoy a lot of patronage especially with long standing lesions. Topical herbal medication induced chemical inflammation of the skin and ulceration and was capable of misdirecting clinical judgement and therapy. Delay in presentation and diagnosis was due to the inability of previous consultations to result in a proper diagnosis while the morbidity associated with topical herbal medication, ulceration, prompted presentation. Health education is pivotal for early presentation. Physicians should subject chronic cervical lymphadenopathy to histologic evaluation for diagnosis and proper treatment as this is crucial for sat- isfactory outcome.

Huge Submental chronic lymphadenopathy may be tuberculous. The effect of topical herbal medication on clinical evaluation should not be underestimated likewise the morbidity. Diagnosis is histologic, long-standing chronic lymphadenopathy without suppuration in a seronegative patient should arouse the diagnosis of noncaseating TB.

\section{REFERENCES}

[1] Olu-Eddo, A.N. and Ohanaka, C.E. (2006) Peripheral lymphadenopathy in Nigerian adults. Journal of Pakistan Medical Association, 56, 405-408.

[2] Adeniji, K.A. and Anjorin, A.S. (2000) Peripheral lymphadenopathy in Nigeria. African Journal of Medicine \& Medical Sciences, 29, 233-237.

[3] Nwagbara, V.I., Asuquo, M.E., Ebughe, G., Agbor, C., Akpan, S., Ugbem, T. and Asuquo, I.M. (2013) Tuberculous lymphadenitis of the neck. Case series. International Journal of Medicine, 1, 4-8.

[4] Olu-Eddo, A.N. and Omoti, C.E. (2011) Diagnostic evaluation of primary cervical adenopathies in a developing country. Pan African Medical Journal, 10, 52.

[5] Shubha, A.B., Sapna, H. and Dinesh Rao, B. (2010) Tuberculous lymphadenitis presenting a diagnostic dilemma. A Case Report. International Journal of Dental Clinics, 2, 48-52.

[6] Udoh, M.O. (2009) Pathogenesis and Morphology of Tuberculosis. Benin Journal of Postgraduate Medicine, 11, 91-96.

[7] Ben, C., Patel, P.S., Bharucha, H., Namaambo, K. and Luo, N. (1996) Importance of human immunodeficiency virus associated lymphadenopathy and tuberculous lymphadenitis in patients undergoing lymph node biopsy in Zambia. British Journal of Surgery, 83, 75-78. doi:10.1002/bjs.1800830124

[8] Thomas, J.O., Ladikpo, J.K. and Yawe, T. (1995) Histopathology of lymphadenopathy in a tropical country. East African Medical Journal, 72, 703-705.

[9] Tan, K.K. (1988) Tuberculous lymphadenitis in Singapore. Singapore Medical Journal, 29, 441-446.

[10] Al-Shohaibani, M.O. (1996) Chronic lymphadenopathy in the eastern province of Saudi Arabia. East African Medical Journal, 73, 533-537.

[11] Sriran Bhat, M. (2009) SRB's mannual of surgery. 3rd Edition, Jaypee, New Delhi, 391-393. 